\title{
CMPO
}

THE CENTRE FOR MARKET AND PUBLIC ORGANISATION

\section{Evaluating Changing Residential Segregation in Auckland, New Zealand, Using Spatial Statistics}

\author{
Ron Johnston, Michael Poulsen and James Forrest
}

\author{
March 2009 \\ Working Paper No. 09/214 \\ Centre for Market and Public Organisation \\ Bristol Institute of Public Affairs \\ University of Bristol \\ 2 Priory Road \\ Bristol BS8 1TX \\ http://www.bristol.ac.uk/cmpo/ \\ Tel: (0117) 3310799 \\ Fax: (0117) 3310705 \\ E-mail: cmpo-office@bristol.ac.uk
}

The Centre for Market and Public Organisation (CMPO) is a leading research centre, combining expertise in economics, geography and law. Our objective is to study the intersection between the public and private sectors of the economy, and in particular to understand the right way to organise and deliver public services. The Centre aims to develop research, contribute to the public debate and inform policy-making.

CMPO, now an ESRC Research Centre was established in 1998 with two large grants from The Leverhulme Trust. In 2004 we were awarded ESRC Research Centre status, and CMPO now combines core funding from both the ESRC and the Trust.

ISSN 1473-625X 


\title{
Evaluating Changing Residential Segregation in Auckland, New Zealand, Using Spatial Statistics
}

\author{
Ron Johnston ${ }^{1}$, Michael Poulsen ${ }^{2}$ \\ and \\ James Forrest ${ }^{2}$ \\ ${ }^{1}$ CMPO, University of Bristol \\ ${ }^{2}$ Macquarie University
}

March 2009

\begin{abstract}
Much work on residential segregation in urban areas has focused on aspatial indices of urban residential segregation, largely ignoring locational aspects of the degree of spatial separation of different ethnic groups. The adoption of measures of global and local spatial autocorrelation has recently been suggested as a way of introducing a more explicit spatial approach to studying segregation. This paper uses two of those measures - Moran's I and Getis and Ord's G* - to explore segregation of the four main ethnic groups in Auckland, New Zealand's largest and most multi-ethnic city, at the four most recent censuses held there. They are used to identify the clusters of census reporting units (meshblocks) where each group is significantly over- and under-represented, and to chart the degree of segregation within such clusters.
\end{abstract}

Keywords: segregation, ethnicity, Auckland, local statistics

JEL Classification: R1

Electronic version: $\underline{w w w . b r i s t o l . a c . u k / c m p o / p u b l i c a t i o n s / p a p e r s / 2009 / a b s t r a c t 214 . h t m l ~}$

\author{
Address for Correspondence \\ CMPO, Bristol Institute of Public Affairs \\ University of Bristol \\ 2 Priory Road \\ Bristol \\ BS8 1TX \\ R.Johnston@bristol.ac.uk \\ www.bristol.ac.uk/cmpo/
}


The issue of ethnic residential segregation has long attracted much academic attention in a wide range of countries. Measuring the degree to which groups are segregated i.e. the extent to which they live apart from members of other groups in relatively exclusive residential areas - has involved the development of a wide range of indices designed to capture separation across a city's residential fabric. (For recent overviews see Reardon, 2007; Feitosa et al., 2007: see also Simpson, 2007.) In a classic paper, Massey and Denton (1988) classified many of these indices into five categories which focus on different aspects of mapped patterns - unevenness, isolation, centralization, clustering, and concentration - and suggested that these were not only conceptually but also empirically separate. According to their argument, therefore, capturing the full nature of segregation was a five-dimensional task, although Johnston, Poulsen and Forrest (2007a), after an empirical re-evaluation of their arguments, argue that it is basically only two-dimensional - one largely aspatial and the other spatial.

Most analysts have focused on just two of those sets of indices, however unevenness and isolation - both of which fall into the aspatial category. For unevenness, most popular have been the index of dissimilarity, which identifies the degree to which the distributions of two ethnic groups differ across the spatial units into which a city is divided, and the associated index of segregation, which compares the distribution of one ethnic group to that of the remainder of the city's population.

For isolation, again two indices have commonly been deployed: the index of exposure identifies the degree to which members of two ethnic groups area separated from each other across the city's constituent areas; the index of isolation summarizes the degree to which members of one group live apart from members of all other groups in relatively exclusive residential areas.

Widespread use of these indices has provided much general information on the residential geographies of different ethnic groups, across cities and over time. But they suffer from a number of drawbacks which mean that they provide only a partial representation of the situation. If the concept of segregation is limited to patterndescription (excluding explicit measurement of the segregation-generating processes: Simpson, 2004; Johnston, Poulsen and Forrest, 2005), then it relates to the extent to which members of a defined group live apart from members of other groups - the complement of which is the degree to which they share residential space. Thus total segregation for a group would involve none of its members living in areas also occupied by members of other groups, whereas a complete absence of segregation for that group would mean that its members form the same share of the population in every area into which the city is divided.

Segregation implies not sharing space and its study calls for different approaches from those based on single-number indices, as in the development of residential area typologies (Johnston, Poulsen and Forrest, 2007b). These, however, also suffer from being largely aspatial (Johnston, Poulsen and Forrest, 2008) and so in this paper we explore the use of spatial statistics to address this issue and provide more explicitly locational insights to the geography of segregation.

\section{ON SEGREGATION INDICES}

A first major drawback of the widely-used single-number indices used is that although they are excellent at identifying the two extreme situations just discussed, they are 
less so at various points along the continuum between them. Take, for example, the index of segregation, which varies between 1.0 (complete segregation) and 0.0 (complete lack of segregation). What does a value of 0.6 indicate? The usual interpretation is that 60 per cent of the members of the group in question would have to be redistributed across the city's constituent areas in order that the group formed the same proportion of the population in every area. Although of value, that figure does not tell us what proportion (if any) of the group's members live in areas from which members of other groups are absent. There may be a relatively high index indicating that the two geographies are very dissimilar - but this does not necessarily mean that some members of the group are living apart from the rest of the population in relatively exclusive districts, nor that some live in areas where they form only a small minority.

A second drawback concerns the degree of variation around an average situation. An index of isolation of 0.6 , for example, indicates that on average across the city there is a 0.6 probability that if you select a member of a given ethnic group at random, then another individual selected at random from within the same spatial unit (the small areas used to calculate the index) is also a member of that ethnic group. The index gives the probability of two neighbours (i.e. individuals selected at random) being from the same ethnic group. But what is the variation around that probability, if any? For some members of the group the probability may be 1.0 (i.e. they live in exclusive enclaves) whereas for others it may be 0.001 (they live in areas where there are virtually no other members of their group) - variation about which a single-number index reveals nothing.

A final major drawback - sometimes referred to as the 'checkerboard problem' - is one of geography. The indices of unevenness and isolation take no account of relative location, of whether, for example, all of the spatial units where one ethnic group is concentrated are clustered together within the same segment of the city or whether there are several smaller and spatially distinct clusters (which is why we term the indices aspatial). If the former situation applies, then it could be argued that members of the group are more segregated than if the latter applied - even if the index of isolation is the same in both cases. In the former case, with the areas of group concentration all clustered together, not only are your near neighbours likely to be from the same ethnic group but so are those who live a little further from your home; in the latter case, people living on the same block as you might have the same ethnic identity but those two blocks away may not.

This last problem has been addressed in a number of ways, initially by calculating indices that combine, say, dissimilarity with clustering (Morgan, 1983; Morrill, 1991; Wong, 1993; Reardon and O'Sullivan, 2004). These pose considerable interpretative difficulties and also suffer from the drawback of giving no indication of any variation around the average situation - hence we do not follow them here. More recently, researchers have deployed techniques developed within the fields of spatial econometrics, much facilitated by the rapid developments of Geographical Information Systems to address the issue. Reardon et al. (2008), for example, have used spatial information theory to introduce a distance-decay effect. Segregation is measured at a variety of spatial scales as a weighted function of the ethnic composition of areal units - with nearby units being weighted most heavily; if the segregation measure is as large for wide areas (i.e. with a relatively weak distance- 
decay effect) as for more constrained areas, this suggests considerable clustering of areas with similar ethnic composition, whereas if it is smaller, this suggests that there are several distinct clusters - but it is suggestive only.

Other explorations of ways to circumvent the checkerboard problem involve the use of local statistics measures of spatial autocorrelation, developed by Anselin (1995) and by Getis and Ord (1992; Ord and Getis, 1995, 2001): Brown and Chung (2006; see also Chung and Brown, 2007), for example, used a variant of the method deployed here to identify significant clusters of various ethnic minority groups within one city; and Lloyd, Shutttleworth and McNair (2004) similarly deployed Anselin's related procedure in their work on religious segregation in Northern Ireland. In this paper, we follow their lead by expanding the use of measures of global and local spatial autocorrelation to analyze the changing patterns of ethnic residential segregation in Auckland, New Zealand using data from four quinquennial censuses over a fifteen-year period. Our alternative approach suggests much greater change in the pattern of segregation there over that period than do the traditional indices, as well as providing much greater appreciation of the extent of spatial separation than the traditional, aspatial indices afford.

Our concern in the procedures outlined here, therefore, is to inject an explicit spatial component to the analysis of segregation patterns. The drawbacks of the indices of unevenness and isolation outlined here also apply to those of concentration, clustering and centralization. With clustering, for example, a single index gives no indication of whether there is a single cluster for the ethnic group in question, or whether there are several, separate clusters. Measures such as the Getis-Ord $G^{*}$ coefficient address that issue directly. But, as will be illustrated here, although they identify the significant clusters, allowing identification of the degree to which a group's members are concentrated therein, they do not also address the issue of the intensity of segregation within those clusters. In this paper we introduce a means of doing that, using $G^{*}$ to identify the parts of the city where ethnic groups are significantly clustered and then examine the ethnic composition of their constituent small areas to identify the degree to which the group members live in relatively exclusive neighbourhoods or share residential space in a multi-ethnic context.

The purpose of this paper, therefore, is to illustrate the benefits of an approach to the analysis of ethnic residential segregation based on the use of local statistics, using as the exemplar a city with a rapidly changing ethnic composition. The traditional indices of segregation and isolation are calculated to indicate the limited amount of information they provide about Auckland's changing ethnic geography, compared to that promoted here. The latter identifies the parts of the city where each ethnic group is significantly concentrated at each census, and examination of the composition of those clusters indicates the degree to which residential space is shared by combinations of the four ethnic groups for which data are available. We are thus able to address questions of where the groups are significantly clustered, what proportion of each group lives within those clusters, how exclusive the areas within the clusters are, and to what extent the groups share residential spaces within and outwith those clusters - over time. This encapsulates much more of the nature of residential segregation than a single index number. 


\section{MULTI-ETHNIC AUCKLAND AND THE LIMITATIONS OF SINGLE- NUMBER INDEXES}

Auckland has emerged as a multi-ethnic city in recent decades, with rapid growth of Pacific Islander and Asian populations joining the indigenous Maori and the majority group characterized in the country's census question on self-assessed ethnicity as having New Zealand European (predominantly UK and Ireland) backgrounds. ${ }^{1}$ The totals shown in Table 1 are taken from a special tabulation prepared by Statistics New Zealand covering the 1991, 1996, 2001 and 2006 censuses, using a common set of small areas (meshblocks, with average populations of 91, 98, 101 and 106 across the four censuses, respectively; some of these contained no resident population at the earlier censuses). The New Zealand European majority component remained relatively stable, growing by only 8 per cent over the 15 -year period - although because of changes in the ethnicity classification, Statistics New Zealand recommends that for comparative purposes members of the 'Other' component should be added to this group, giving 1991 and 2006 totals of 636,102 and 771,360 respectively, and 21 per cent growth over the period. The Maori population grew by slightly more than that (29 per cent), the Pacific Islander component by twice as much again (57 per cent), and the small 1991 Asian population increased by 339 per cent over the fifteen years.

These four groups are not evenly distributed through the city's residential fabric, as earlier studies have demonstrated (Murphy et al., 2000; Ho and Bedford, 2006; Johnston, Poulsen and Forrest, 2008). ${ }^{2}$ Table 2 provides comparative data for the last four censuses on the relative degree of spatial separation of the four groups, using two of the commonly-deployed indices:

- The index of segregation (a measure of the unevenness of two distributions in this case comparing the group in question with the remainder of the population); and

- The index of isolation (a measure of exposure - in this case the probability that one member of the group in question selected at random will meet another member of that group selected at random from the same meshblock).

Each is expressed as a proportion ranging between 0.0 and 1.0; the higher the index, the greater the degree of segregation/isolation. Because the index of isolation is sensitive to the group's overall proportion of the urban population, it should be modified to take this into account when making comparisons over time. The resulting modified indices of isolation (using formulae developed by Cutler, Glaeser and Vigdor, 1999, and Noden, 2000), also vary between 0.0 and 1.0; the higher the value, the greater the group's degree of spatial separation relative to its overall size.

All of these index values in Table 2 illustrate one of the problems of using such measures in situations where spatial separation is not marked; all are intermediate values between 0.0 and 1.0 which, although they provide relative statements on the degree of unevenness and isolation, give no indication of the degree to which at least some members of any group live apart from others, in residential areas largely exclusive to their group only.

The indices of segregation show that at all four dates Pacific Islanders were more separated from the rest of the population than were the other three groups, but there was very little change over time for any group. The indices of isolation, on the other 
hand, indicate much greater spatial separation of the New Zealand Europeans than any of the other three: in 1996 , for example, there was a 0.80 probability that a member of that group selected at random would have another group member living in the same meshblock, a value nearly twice as large as that for Pacific Islanders and nearly four times as large as for Maori and Asians. Over time, those indices suggest a slight decline in the isolation of New Zealand Europeans (i.e. greater residential mixing), little change for Maori, a slight increase for Pacific Islanders, and a substantial increase for Asians. However, the Asian share of Auckland's population tripled from 5.6 per cent in 1991 to 16.8 per cent fifteen years later, and this will influence the size of the index of isolation. (With a random distribution of populations across the meshblocks, there would be a 0.056 probability of two Asians meeting in the same meshblock in 1991, but a 0.168 probability in 2006.) The modified index takes this into account.

The patterns shown by the modified indices in the final block of Table 2 are similar but more muted - to those in the second block. New Zealand Europeans and Pacific Islanders have been most separated spatially, although whereas the degree of separation fell for the former group over the fifteen-year period, it increased for the latter. The spatial separation of Asians grew substantially as the group increased in size, but there was no change in the situation for Maori, who were by far the least isolated spatially by the period's end.

\section{INTRODUCING SPATIAL CLUSTERING}

As well as giving no indication of the amount of variation in the residential situation of members of each ethnic group - did all Asians in Auckland in 2006 have the same probability (0.34) of having another Asian as a meshblock neighbour, for example? the indices take no account of the relative location of meshblocks with similar ethnic composition. Are those where Asians form a large proportion of the population spatially clustered in the same part(s) of the city, or are they randomly distributed across the residential milieu?

Global measures of spatial autocorrelation have long been available and deployed in spatial econometrics; recent developments of local statistics have enabled much more geographical specificity in analyzing spatial patterns. We extend their use here, looking first at the global pattern of segregation within Auckland and then at its local variability.

\section{THE GLOBAL PATTERN}

One of the longest-established and widely-deployed measures of spatial clustering (autocorrelation) is Moran's I (Moran, 1950), defined as:

$I=\left[\left[\sum_{i}^{n} \sum_{j}^{n} w_{i j} *\left\{\left(x_{i}-\bar{X}\right) *\left(x_{j}-\bar{X}\right)\right\}\right] / \sum\left(x_{i}-\bar{X}\right)^{2}\right] * n / \mathrm{S}_{\mathrm{o}}$

where

$x_{\mathrm{i}}$ and $x_{\mathrm{j}}$ are the percentages of the population of areas $\mathrm{i}$ and $\mathrm{j}$ respectively in ethnic group $\mathrm{x}$; 
$\bar{X}$ is the mean percentage of the population of all areas in ethnic group $\mathrm{x}$;

$\mathrm{w}_{\mathrm{ij}}$ is the spatial proximity weight for areas $\mathrm{i}$ and $\mathrm{j}$, coded 1 if they are adjacent and 0 otherwise;

$n$ is the number of areas into which the city is divided; and

$\mathrm{S}_{\mathrm{o}}$ is the sum of all $\mathrm{w}_{\mathrm{ij}}$ across all $n$ areas.

The $I$ coefficient is thus a measure of spatial autocorrelation, of the degree to which adjacent values of the variable in question are similar (i.e. differ from the mean value in the same direction and by a similar magnitude), relative to the differences between all pairs. An associated Z-score can be calculated to give a measure of I's statistical significance.

As an overall measure of spatial clustering, Moran's I summarizes the general pattern, and its values can be compared both across ethnic groups and across time. The $Z$ scores for the coefficients in Table 3 show that clustering was highly significant for each of Auckland's four ethnic groups at all four censuses analyzed here. Each was much more clustered as a percentage of the meshblock populations than would occur if its members were randomly distributed through the urban residential mosaic. Nevertheless, despite their statistical significance the $I$ values are relatively small (they can be interpreted in the same way as correlation coefficients) and do not suggest intensive clustering of any of the four groups.

The relative size of the coefficients indicates that each of the four groups became more spatially clustered over the four censuses, although the increase was much greater for Maori and, especially, Pacific Islander populations than for the New Zealand Europeans and Asians. (There were 40 and 32 per cent increases in the value of $I$ for the Pacific Islanders and Maori respectively, compared to only 7 per cent for Asians - despite their burgeoning absolute and relative growth over the period - and 9 per cent for New Zealand Europeans.) Pacific Islanders and Maori were also much more clustered at each census - and increasingly so across the four censuses - than were members of the other two groups; in relative terms, according to the $I$ coefficients, clustering of Pacific Islanders was three times greater than that of New Zealand Europeans by 2006.

Moran's I suffers from the same problem already identified for other single-number indices of segregation, however. It provides a general overview only. It does not address the question of whether a highly clustered group is concentrated into just one or several parts of the city, for example, and says nothing about the ethnic composition of the areas where a group is clustered. Like the indices of dissimilarity, segregation, isolation and exposure it provides a simple summary of the geography but reveals nothing of its potential complexity. For that, we turn to measures of local clustering.

\section{LOCAL STATISTICS}

Moran's I provides no information with which to identify the location, size, number and intensity of each group's clusters. Is there just one, or are there several clusters in different parts of the city, perhaps of varying size and intensity. Several measures of local clustering have been developed recently. We employ one $-G^{*}-$ developed by Getis and Ord (1992; Ord and Getis, 1995, 2001), which was designed to identify 
local 'hot-spots', areas of clustering significantly different from the average situation across the mapped space. $G^{*}$, as operationalized in the ArcGIS software package, and which id distributed as a Z-coefficient, is defined as (Getis and Ord, 1992, 190):

$$
G_{i}^{*}=\left[\sum_{j}^{n} w_{i j}\left(x_{j}-\bar{X}\right) \sum_{j}^{n} w_{i j}\right] /\left[S \sqrt{ }\left\{n \sum_{j}^{n} w_{i j}^{2}-\left(\sum_{j}^{n} w_{i j}\right)^{2}\right\} /(n-1)\right]
$$

where

$x_{\mathrm{j}}$ is the percentage of the population of area $\mathrm{j}$ in ethnic group $x$;

$\bar{X}$ is the mean percentage of the population of all areas in ethnic group $\mathrm{x}$;

$\mathrm{w}_{\mathrm{ij}}$ is the spatial proximity weight for areas $\mathrm{i}$ and $\mathrm{j}$, coded 1 if $\mathrm{j}$ is within $d$ metres of $\mathrm{i}$, and 0 otherwise;

$n$ is the number of areas into which the city is divided;

$S$ is

$$
\sqrt{ }\left[\left\{\sum_{j}^{n} x_{j}^{2}\right\} / \mathrm{n}\right]-\bar{X}^{2}
$$

$d$ in this case is 1000 metres;

and

$G_{i}^{*}$ is the value (distributed as $Z$ ) for area i.

For each of the separate areas - meshblocks in Auckland - we therefore get a value of $G^{*}$ which indicates, for the ethnic group under consideration, the degree to which it has a similar share of the area population as neighbouring areas, relative to the citywide average. If $G^{*}$ is large and positive, this indicates that neighbouring areas to the one being considered on average have relatively large percentage shares of the ethnic group within their population, whereas if $G^{*}$ is negative, then area $i$ and its nearneighbours have relatively low percentage shares of that group (relative, that is, the overall urban average). Because $G^{*}$ is distributed as $Z$, the determination of whether its value is large or small can be made using traditional statistical significance levels. If $G^{*}$ is statistically insignificant for area $i$, this means there is no clustering focused on that area of adjacent meshblocks all having either relatively large or small percentages of the relevant ethnic group living there.

For the present analyses, we have taken a distance band (d) of 1000 meters, so that the $G^{*}$ coefficient for each meshblock averages the percentage in the relevant ethnic group across all meshblocks within that distance, including itself. It thus identifies the degree to which all of the meshblocks within 1000 meters of its centroid have percentages of the ethnic group that are either significantly above or significantly below the overall average. Clearly the choice of distance band is very important; very different radii might produce considerably different outcomes - in degree if not in kind (i.e. the same core clusters would be identified, but their extent would vary). We selected 1000 metres because: (a) the minimum distance between the centroids of meshblocks is 16.06 metres; (b) the average is 181.4 metres; and (c) the maximum is 5723.3 metres. Thus on average a distance of 1000 metres should encompass about five other meshblocks in any direction (a reasonable estimate, also, of the maximum walking distance that people will undertake within neighbourhoods). Clearly research is needed to evaluate the robustness of findings using other distances and also whether distance should be weighted - to emphasise closer neighbours (as in Reardon et al., 2008). On the urban periphery, where there are few neighbours within the threshold 
distance, the average is closer to that of the individual meshblock being considered. As the distance band is widened, so the likelihood of an average significantly different from that for the entire urban area is reduced.

Mapping the $G^{*}$ values indicates the groups of neighbouring meshblocks in which an ethnic group is: (a) significantly more numerous than if it were randomly distributed across all meshblocks (with $G^{*}$ values greater than a given threshold: 2.58 indicates significant clustering at the 0.01 level, for example); (b) significantly less numerous than if it were randomly distributed across all meshblocks $\left(G^{*}\right.$ values below -2.58 at the 0.01 level, for example); and (c) neither significantly more nor significantly less numerous than if it were randomly distributed across all meshblocks $\left(G^{*}\right.$ values between +2.58 and -2.58 at the 0.01 level, for example). Not all of the meshblocks within 1000 meters of the targeted block may have a similar percentage of the relevant ethnic group living there, but the clustering procedure identifies proximal meshblocks which overall have significant over- or under-representation of the relevant group; there could, therefore, be some heterogeneity within the identified clusters. Similarly, within the parts of the city lacking any significant clustering there may be meshblocks with high percentages from one or more of the groups but these are relatively isolated, with few, if any, similarly constituted meshblocks nearby.

The distributions of $G^{*}$ values using the usual thresholds of significant at the 0.05 and 0.01 levels for each ethnic group at each of the four censuses are shown in Table 4. Thus, for example, of the 7950 populated meshblocks in the 1991 census, 2928 had a $G^{*}$ value greater than +2.58 for New Zealand Europeans, indicating that there was a probability of less than 0.01 that it and its neighbouring meshblocks within 1000 meters would have such large percentages living there relative to the city-wide average; a further 513 meshblocks had a probability between 0.05 and 0.01 that they and their near-neighbours would have such large percentages. Complementing that, 1514 meshblocks had $G^{*}$ values smaller than -2.58 , indicating a probability of less than 0.01 that on average they and neighbouring meshblocks had percentages of New Zealand Europeans much smaller than the metropolitan average; a further 269 had at least a 0.05 probability of such below-average clustering. Finally, 2726 of the meshblocks (just over one-third of the total) had statistically-insignificant $G^{*}$ values (i.e. less than a 0.05 probability), indicating an absence of local clustering of meshblocks with New Zealand European percentages either significantly above or significantly below the average.

One general feature of the patterns applying to all four ethnic groups in Table 4 is that each experienced an increase in the number of meshblocks in the -0.01 row -i.e. in the number of meshblocks where there was significant clustering of areas from which the group was relatively absent. This suggests a growing polarization of the city, an increase in the extent of the clusters where each group is significantly small in number relative to its citywide proportion. A growing proportion of the city's residential areas was characterized by a relative absence of one or more of the four ethnic groups. Complementing this, there are different other trends for the various groups. For New Zealand Europeans, there was a decline in the number of meshblocks in clusters where the group was over-represented, whereas for Asians there was a substantial increase in that category - balanced (given also the decrease in the number with significant under-representation) by a substantial decline in the number of meshblocks where there was neither significant under- nor over-representation in neighbouring 
meshblocks. For Auckland's Asian population, as their number grew over the fifteen years the city became increasingly divided into areas where they were either significantly under- or over-represented.

The information on the distribution of meshblocks according to the identified clusters is supplemented in Table 5 by data on the distribution of members of each ethnic group according to the typology of $Z$-scores. Much of this shows considerable stability across the fifteen-year period; Pacific Islanders, for example, had by far the largest share of their population (c.65.5 per cent) living in clusters where their share of the population was much greater than expected, a situation that hardly changed across the four censuses. For Asians, however, there was a substantial increase in the share living in such areas, as their total population burgeoned, and a compensatory decline in the share living in the 'insignificant' category where the meshblocks' populations were ethnically most mixed. For New Zealand Europeans, an increasing share lived in the larger number of areas where they were significantly underrepresented: they formed a small minority only of the population in an increasing proportion of the city. The changes for the Maori were relatively similar to those for the New Zealand Europeans, although the former were more segregated overall, with over half of them living in clusters where the group was significantly over-represented in 2006 compared to 38 per cent for the latter.

Maps of the distribution of the $G^{*}$ values for each ethnic group at each of the four censuses are in Figures 1-4. For the New Zealand Europeans they show a geography characterized by two major features, consistent with the overall patters identified in Tables 4 and 5. The 1991 map (Figure 1) shows major concentrations where this group is significantly more numerous than expected (areas with $G^{*}$ values greater than +2.58 ) on most of the North Shore immediately north of the harbour and in four major segments of the metropolitan area's central isthmus. Much of south Auckland comprised a block of territory from which New Zealand Europeans were relatively absent $\left(G^{*}\right.$ values greater than -2.58$)$ and most of the metropolitan fringe comprised areas where they were neither significantly over- nor under-represented. This geography had changed very little in 1996 and 2001 but by 2006 two major shifts were apparent. On the North Shore, the area of New Zealand European predominance was much reduced in size (replaced largely by areas where they were neither undernor over-represented), whereas in southern Auckland and in the southwestern segment of the central isthmus the areas where New Zealand Europeans were relatively absent had extended substantially from the 1991 core.

Whereas the maps for New Zealand Europeans changed considerably over the 15-year period, those for Maori did not (Figure 2). The 1991 pattern of major concentrations in southern Auckland, complemented by their absence from much of the North Shore, the central isthmus and the eastern suburbs, had changed only slightly by 2006 , mainly through extensions to the areas of concentration and absence; an established residential geography was largely unaltered. The same occurred with the Pacific Islanders (Figure 3); the areas of under- and over-representation in 2006 were - with some slight expansion - the same as those of 1991. Despite substantial growth of the Pacific Islander population, their residential enclaves remained consistent in their location and extent. This was not the case with the Asian ethnic group, however. In 1991, the relatively small population was significantly clustered through much of the central isthmus and the eastern suburbs (Figure 4), with few areas where they were 
significantly under-represented: apart from those concentrations, Asians were relatively evenly distributed through much of the metropolitan area then. By 1996 there was a substantial (dominantly Korean ${ }^{3}$ ) cluster on the North Shore and the eastern suburbs cluster had expanded considerably. That pattern intensified over the next decade, so that by 2006 there were three major clusters of meshblocks where Asians were over-represented, along with a greater proportion of the metropolitan area where they were significantly under-represented.

The maps suggest considerable stability in the clustering pattern: once an ethnic group became over-represented in an area, it tended to remain relatively numerous there. This is confirmed by Table 6, in which cluster membership in 1991 is cross-classified with that for 2006 for all meshblocks; a threefold typology is used with the 0.01 significance $G^{*}$ values of -2.58 and +2.58 as the thresholds (recalling that relatively few meshblocks had $G^{*}$ values significant at the 0.05 level but not the 0.01: Table 4). For both the Maori and the Pacific Islanders the situation is very stable. Each had 83 per cent of the meshblocks in the same clustering category at the two dates and few of the meshblocks where they were significantly under-represented in 1991 were not in the same category fifteen years later. With the Pacific Islanders much more than the Maori, however, there was substantial movement between the over-represented and insignificant categories, in both directions, suggesting some shifts on the cluster margins.

Changes were much greater for the other two groups. For Asians, there were substantial shifts between most pairs in the categorization, the only exception being that very few meshblocks moved from the over-represented to the under-represented clusters. As the Asian population grew from its small original size, therefore, there was considerable fluidity in the ethnic composition of the areas where they settled. Some meshblocks became parts of clusters where Asians were over-represented, but others originally in such clusters became detached from them. And as the population grew, so some meshblocks in areas where initially they were neither under- nor overrepresented became less popular for Asians and were reallocated to the underrepresentation clusters whereas others became more popular and shifted into the overrepresentation clusters (as indicated by the central row in the Asian block of Table 6).

Finally, only just under two-thirds of the meshblocks retained the same classification for the New Zealand Europeans. By far the largest shift was away from the clusters where they were significantly over-represented in 1991, with more than one-third of those meshblocks being in the 'insignificant' category fifteen years later. This suggests considerable de-segregation, as some of the clusters of adjacent meshblocks where New Zealand Europeans predominated in 1991 were substantially reduced in their extent, indicating greater ethnic mixing there over time. At the other extreme, approximately one-quarter of all meshblocks where New Zealand Europeans were under-represented in 1991 were in the 'insignificant' category with more mixed populations in 2006; a similar percentage of the meshblocks moved in the opposite direction.

\section{SHARED RESIDENTIAL SPACES}

One clear feature of the maps in Figures 1-4 is the degree of overlap of the major clusters, notably of the areas where Maori and Pacific Islanders are significantly over- 
represented. Comparison of Figures 2 and 3, for example, shows that in 2006 a large swathe of the southern suburbs contained significant over-representation of both groups. The maps were not identical, however: there was a much larger concentration of Maori than of Pacific Islanders in the western suburbs and in the far south, for example, and there were parts of the southern central isthmus with significant concentrations of Pacific Islanders but not Maori.

The extent of this overlap is captured in Table 7, which cross-classifies the three-way categorization of meshblocks for each pair of ethnic groups in 2006. The three comparisons on the top row show a major contrast. A very large percentage (83) of the meshblocks where Pacific Islanders are significantly over-represented have significant under-representation of New Zealand Europeans whereas fully threequarters of the meshblocks where Pacific Islanders are over-represented also have Maori over-representation and virtually none have significant Maori underrepresentation. Thus in much of Auckland the areas of Maori and Pacific Islander concentration overlap, with New Zealand Europeans relatively absent from those areas. ${ }^{4}$ The Asian geography is less exclusive, however. A little under one-third of the meshblocks where Pacific Islanders are over-represented also have Asian overrepresentation, for example, whereas a third of those with Asian over-representation have Pacific Islander under-representation. Asian clusters are slightly more distinct from those of both Maori and New Zealand Europeans, but there is still considerable mixing.

The degree of overlap is summarized in Table 8, which shows the percentage of meshblocks which had a significant over-representation $\left(G^{*}\right.$ value of +2.58 or greater) for each combination of the four ethnic groups. Not surprisingly, none had all four significantly over-represented, but a small percentage had three of the four so classified - the great majority of them having concentrations of Pacific Islanders, Maori and Asians. By far the largest overlap, however, and increasing in size over the four censuses, was of concentrations of Pacific Islanders and Maori; by 2006 over 13 per cent of all meshblocks were in clusters where both of those groups were overrepresented. The sharing of space between clusters of Pacific Islanders and Asians declined over time, as did that between clusters of New Zealand Europeans and Asians. This is shown for 2006 in Table 9, which gives the percentage of each ethnic group living in the various shared-space categories. Many more Pacific Islanders (nearly two-thirds) lived in clusters of meshblocks where two or more groups were significantly over-represented, than was the case with the other three groups: New Zealand Europeans were the least likely to be living in clusters of meshblocks where they and at least one other ethnic group were over-represented.

\section{THE INTERNAL STRUCTURE OF THE CLUSTERS}

Using the $G^{*}$ methodology we have identified the major clusters within Auckland occupied by the different ethnic groups and charted their changing geographies over a fifteen-year period of substantial change in the city's multi-ethnic composition. But how ethnically homogeneous are the clusters? Just because the relevant groups are much larger there than elsewhere in the city - as percentages of the total population this does not imply that they dominate the local populations. To address the homogeneity issue, therefore, we look at patterning within the clusters, using each group's percentage share of every meshblock's population. 
Figure 5 does this for 2006, indicating very considerable differences across the four groups. The extreme case is clearly the New Zealand European situation. The majority of the meshblocks in each of the clusters where they are significantly overrepresented have populations where New Zealand Europeans form at least 60 per cent of the total and in several - such as the southwestern cluster - almost all of the meshblocks contain at least 80 per cent of their populations drawn from this group. By contrast, the situation for Asians indicates very much lower levels of spatial separation across nearly all of the clusters where they are significantly overrepresented. On both the North Shore and in the eastern suburbs, for example, there are virtually no meshblocks where Asians formed more than one-fifth of the total population in 2006: they were relatively clustered into those areas but nevertheless formed only a minority of the local population. Even in the areas where they were more numerous - in parts of the major cluster in the central isthmus, for example, and on the western edge of the south Auckland clusters - there were relatively few where they formed more than 40 per cent of any meshblock total.

There is also a substantial contrast between the two Polynesian groups. The pattern for the Maori, for example, is quite similar to that for Asians, with few meshblocks and certainly almost none outside the cluster in the far south - where they form more than 40 per cent of the population. Whereas Maori are relatively clustered into certain parts of the metropolitan area but form a minority of the population in most of the residential areas there, Pacific Islanders, on the other hand, are much more likely to be in a majority in substantial parts of the areas where they are clustered, notably in the wide swathe of meshblocks immediately south of the isthmus, in most of which Maori form a significant minority.

The detail in Figure 5 and similar maps for the earlier censuses is summarized in Table 10 in which, for each ethnic group, the meshblocks are placed into the same three categories as in Table 6:- where the group is significantly under-represented at the 0.01 level; +, where it is significantly over-represented at that level; and I, where it is neither under- nor over-represented. These show four very different patterns of intra-cluster homogeneity-heterogeneity. For example, the first block in the first row shows that where New Zealand Europeans were significantly over-represented in 1991 (the column headed ' + '), in 86 per cent of those meshblocks they comprised at least 80 per cent of the block population, whereas in a further 11 per cent they comprised 60-79 per cent. In those where they were under-represented, on the other hand (the column headed '-') only 14 per cent of the meshblock populations were 80 per cent or more from that ethnic group, whereas in 33 per cent less than 20 per cent of the population claimed New Zealand European ethnicity.

Among the four groups, the pattern for the Maori shown in Table 10 is in many ways the simplest. They comprised less than 20 percent of the population in the great majority of meshblocks at each census; they formed 40 per cent or more of the total in only 9 per cent of the 7950 in 1991, for example, and between 20-39 per cent in a further 39 per cent. Even in the areas where the Maori were clustered at each date, therefore, they formed less than 20 per cent of the meshblock population in approximately half of the cases, and in only about one-tenth of all meshblocks at each census did they comprise more than 40 per cent of the total - with their percentage never exceeding 79 and being greater than 59 in very few. Thus even where they were 
clustered, in most of those territorial blocks Maori formed less than half of the population: they were concentrated into certain parts of the city, but not highly segregated there - a situation that was consistent throughout the period.

Pacific Islanders were more segregated from the other ethnic groups within their territorial clusters - a situation that was enhanced across the four censuses. In 1991, they formed less than one-fifth of the populations in the clusters where they were over-represented in 39 per cent of all such meshblocks, a figure which fell to only 26 per cent by 2006. As the Pacific Islander population increased, it became spatially more separated into relatively exclusive residential areas, increasingly dominating the clusters which, as Table 4 shows, did not expand. By 2006, Pacific Islanders formed 60 per cent or more of the population in fully one-quarter of all the meshblocks in the clusters where they were over-represented then. Pacific Islander segregation within their significant clusters was much greater than that of the Maori.

A similar pattern applied to the burgeoning Asian population; whereas Asians formed less than one-fifth of the population in 89 per cent of the meshblocks within their clusters in 1991, fifteen years later this was the case in only 25 per cent. On the other hand, by 2006 there were fewer meshblocks within the Asian clusters where they formed 40 per cent or more of the population in 2006 (31 per cent of those meshblocks) compared with the situation for Pacific Islanders (47 per cent of all meshblocks in their clusters). Asians have become more clustered, but do not dominate local populations within those clusters to the same extent as the Pacific Islanders.

Finally, Table 10 shows that the New Zealand Europeans were Auckland's most segregated ethnic group, even though many of them lived in relatively mixed residential areas. Thus many - though a substantially reduced percentage in 2006 compared to 1991 - of the meshblocks in the clusters where New Zealand Europeans are significantly under-represented still had 60 per cent or more of their populations drawn from that ethnic group: significant under-representation did not mean absence from many parts of the city, although in approximately one-third of all meshblocks there they formed less than 20 per cent of the total population. At the other extreme, New Zealand Europeans predominated in the meshblocks in their positive clusters, where they were over-represented, to a much greater extent than is the case with the other three ethnic groups. Nevertheless, this predominance is declining.

\section{CONCLUSIONS}

This paper has substantially extended recent suggestions that measures of spatial autocorrelation be adopted for the study of ethnic residential segregation in urban areas. Indices of both global - Moran's $I$ - and local - Getis and Ord's $G^{*}$ autocorrelation have been deployed in a study of Auckland's residential mosaic, alongside traditional - aspatial - single-number indices of segregation and isolation. Introducing those spatial measures has allowed us to evaluate not only where different ethnic groups are clustered but also how intense that clustering is - aspects of segregation that cannot be addressed using the single-number indices.

The measures of local spatial autocorrelation in particular have identified and illustrated aspects of residential segregation in that increasingly multi-ethnic city 
which the traditional measures did not reveal. Using $G^{*}$, we have mapped those parts of the urban area in which each group was both significantly under- and overrepresented, relative to the urban area average, as well as those where there was no significant difference from a random allocation of ethnic groups. Having identified those clusters, we could then evaluate what share of the groups' population they contained, as an overall indicator of concentration into clearly-defined clusters, substantially extending other work on that issue (Johnston, Poulsen and Forrest, 2008). We have also identified changes in those patterns, areas where two or more groups overlapped in significant concentrations, and mapped the degree of concentration within each cluster.

Results show that although each of the city's four ethnic groups was significantly clustered in certain areas and under-represented in others, New Zealand Europeans were the most likely to live in clusters of neighbourhoods within their major clusters where they formed 80 per cent or more of the local population, whereas Asians were least likely to live in districts where they formed more than 20 per cent of the local population, even in those parts of the city where they were significantly clustered. The two Polynesian groups lay between those extremes, and also overlapped much more: areas where one was over-represented also tended to be areas where the other was also. But in general Pacific Islanders were much more likely, within those clusters, to live in neighbourhoods where their co-ethnics predominated than was the case with Maori.

The outcome suggests considerable potential for the wider application of local spatial autocorrelation statistics in studies of residential segregation, extending very substantially the amount of information that can be gleaned from census data about segregation patterns. They address the checkerboard issue by focusing on the geography of residential clustering, and thus offer much greater insights than the, aspatial, single-number indices traditionally used in such studies. Further work is needed exploring the method's robustness, in a number of areas. Clearly the choice of a 1000-metre distance band in the calculation of $\mathrm{G}^{*}$ will have an impact on the extent of the clusters. Different distances will undoubtedly produce different cluster configurations: longer distances will almost certainly generate larger clusters, shorter distances smaller, more fragmented cluster patterns. Weighting distances - as in the Geographical Weighted Regression technique - will place greater emphasis on nearby areas, and again probably result in a more fragmented clustering pattern. Similarly selection of the critical thresholds - the significance levels determining membership of a cluster - can have a substantial impact: the larger the threshold the fewer areas that will be included within the clusters. And there are undoubtedly edge effects areas on or near to the city's boundaries will have fewer other areas within the specified distance band than those more centrally located within the urban fabric; one way to tackle these might be to use the 'bespoke neighbourhood' approach to the study of contextual affects (e.g. McAllister et al., 2001), expanding the group of areas beyond that for which $G^{*}$ is being measured until they reach a population threshold (e.g. the minimum number of areas needed to obtain a population of, say, 5000).

There can be no strict rules governing these choices - much will depend on the size of the areas used (the meshblocks in the current example) and particular situations may call for specific choices. The scale effect could be built into the study - as in Reardon et al. (2009) - with the degree of clustering and the intensity of segregation within the 
clusters being measured at a number of scales (distance bands of 500, 100, 1500 and 2000 metres, for example), which could be particularly valuable for comparative studies. The potential is substantial. This paper has illustrated that, showing for one increasingly multi-ethnic city how a combination of measures of local as against global clustering can be used to identify areas where groups are relatively over- and under-concentrated plus absolute indicators of the ethnic composition of areas within those clusters identifies a range of features of ethnic segregation there that traditional approaches cannot discern. Analysing complex geographies requires techniques suited to the purpose.

\section{Notes}

${ }^{1}$ Ethnicity is recorded in the New Zealand censuses using a self-identification question. A small proportion of respondents have used the opportunity of recording joint ethnicity.

${ }^{2}$ Johnston, Poulsen and Forrest's (2008) paper did not have available data for a common set of meshblocks, hence the slight differences between the indices reported there and here.

${ }^{3}$ Data subdividing the Asian population is not available at the meshblock scale, but is at the lager census areal unit scale, which enables this distinction to be identified (see Johnston, Poulsen and Forrest, 2008).

${ }^{4}$ This sharing of residential space by the two Polynesian ethnic groups undoubtedly reflects the allocation policies for state (i.e. public) housing (Johnston, Poulsen and Forrest, 2008).

\section{REFERENCES}

BROWN, L. A. \& S.-Y. CHUNG. (2006), Spatial Segregation, Segregation Indices and the Geographical Perspective. Population, Space and Place 12: 125-43

CHUNG, S.-Y. \& L. A. BROWN. (2007), Racial/Ethnic Residential Sorting in Spatial Context: Testing the Explanatory Frameworks. Urban Geography 28: 312339.

CUTLER, D. M., E. L. GLAESER, \& J. L. VIGDOR. (1999), The Rise and Decline of the American Ghetto. Journal of Political Economy 107: 456-506.

FEITOSA, F. F., G. CAMARA, A. M. V. MONTEIRO, T. KOSCHITZKI \& M. P. S. SILVA. (2007). Global and Local Spatial Indices of Urban Segregation. International Journal of Geographical Information Systems 21: 299-323.

FRIESEN, W., L. MURPHY, R. KEARNS, \& E. HAVERKAMP. (2000). Mapping Change and Difference: a Social Atlas of Auckland. Auckland: University of Auckland, Department of Geography. 
GETIS, A. \& J. K. ORD. (1992). The Analysis of Spatial Association by use of Distance Statistics. Geographical Analysis 24: 189-206.

HO, E. \& R. D. BEDFORD. (2006). The Chinese in Auckland: Changing Profiles in a More Diverse Society. In From Urban Enclave to Ethnic Suburb: New Asian Communities in Pacific Rim Countries, edited by W. Li, 203-230. Honolulu: University of Hawai' I Press.

JOHNSTON, R. J., M. F. POULSEN \& J. FORREST. (2005). On the Measurement and Meaning of Segregation: a Response to Simpson. Urban Studies 42: 12211227

JOHNSTON, R. J., M. F. POULSEN \& J. FORREST. (2007a). Ethnic and Racial Segregation in U.S. Metropolitan Areas, 1980-2000: the Dimensions of Segregation Revisited. Urban Affairs Review 42: 479-504.

JOHNSTON, R. J., M. F. POULSEN \& J. FORREST. (2007b). The Geography of Ethnic Residential Segregation: a Comparative Study of Five Countries. Annals of the Association of American Geographers 97: 713-738.

JOHNSTON, R. J., M. F. POULSEN \& J. FORREST. (2008). Asians, Pacific Islanders and Ethnoburbs in Auckland, New Zealand. Geographical Review 98: 214-241.

LLOYD, C., I. SHUTTLEWORTH, I. \& D. MCNAIR. (2004). Measuring Local Segregation in Northern Ireland. Available at http://www.qub.ac.uk/cstar/selectedoutputs.htm.

MACALLISTER, I., JOHNSTON, R. J., PATTIE, C. J., TUNSTALL, H., DORLING, D. F. L. \& ROSSITER, D. J. (2001). Class Dealignment and the Neighbourhood Effect: Miller Revisited. British Journal of Political Science, 31, 41-60.

MASSEY, D. S. \& N. A. DENTON. (1988). The Dimensions of Residential Segregation. Social Forces 67: 281-315.

MORAN, P. A. P. (1950). Notes on Continuous Stochastic Phenomena. Biometrika 37: 17-33.

MORGAN, B. S. (1983). A Temporal Perspective on the Properties of the Index of Dissimilarity. Environment and Planning A 15: 379-89.

MORRILL, R. L. (1991). On the Measure of Spatial Segregation. Geography Research Forum 11: 25-36.

NODEN, P. (2000). Rediscovering the Impact of Marketisation: Dimensions of Social Segregation in England's Secondary Schools. British Journal of Sociology of Education 21: 372-390.

ORD, J. K. \& A. GETIS. (1995). Local Spatial Autocorrelation Statistics: Distributional Issues and an Application. Geographical Analysis 27: 286-306. 
ORD, J. K. \& A. GETIS. (2001) Testing for Local Spatial Autocorrelation in the Presence of Global Autocorrelation. Journal of Regional Science 41: 411-432.

REARDON, S. F. (2006). A Conceptual Framework for Measuring Segregation and its Association with Population Outcomes. in Methods in Social Epidemiology edited by J. M. Oakes and J. S. Kaufman, San Francisco: Jossey-Bass, pp. 169-192.

REARDON, S. F., C. R. FARRELL, S. A., MATTHEWS, D. O'SULLIVAN, K. BISCHOFF \& G. FIREBAUGH (2009) Race and Space in the 1990s: Changes in the Geographic Scale of Racial Residential Segregation, 19902000. Social Science Research, 38, 55-70.

REARDON, S. F., S. A. MATTHEWS, D. O'SULLIVAN, B. A. LEE, G. FIREBAUGH, C. R. FARRELL \& K. BISCHOFF. (2008). The Geographic Scale of Metropolitan Racial Segregation. Demography 45: 489-514.

REARDON, S. F. \& D. O'SULLIVAN. (2004). Measures of Spatial Segregation. Sociological Methodology 34: 121-62.

SIMPSON, L. (2004). Statistics of racial segregation: Measures, Evidence and Policy. Urban Studies 41: 661-681.

SIMPSON, L. (2007). Ghettos of the Mind: the Empirical Behaviour of Indices of Segregation and Diversity. Journal of the Royal Statistical Society A 170: 40524.

WONG, D. W. S. (1993). Spatial Indices of Segregation. Urban Studies 30: 559-72. 


\section{CAPTIONS}

Figure 1. The clusters within Auckland where New Zealand Europeans were significantly over- $\left(\mathrm{G}^{*}=+2.58<\right)$ and under- $\left(\mathrm{G}^{*}=-2.58<\right)$ at the four census dates.

Figure 2. The clusters within Auckland where Maori were significantly over- $\left(\mathrm{G}^{*}\right.$ $=+2.58<)$ and under- $\left(\mathrm{G}^{*}=-2.58<\right)$ at the four census dates.

Figure 3. The clusters within Auckland where Pacific Islanders were significantly over- $\left(G^{*}=+2.58<\right)$ and under- $\left(G^{*}=-2.58<\right)$ at the four census dates.

Figure 4. The clusters within Auckland where Asians were significantly over- $\left(\mathrm{G}^{*}\right.$ $=+2.58<)$ and under- $\left(G^{*}=-2.58<\right)$ at the four census dates.

Figure 5. The proportion of the meshblock population for each group within the clusters where it was significantly over-represented in 2006. 
Table 1. The Ethnic Composition of Auckland's Population, 1991-2006

\begin{tabular}{lrrrr}
\hline & 1991 & 1996 & 2001 & 2006 \\
\hline NZ European & 636,000 & 666,825 & 663,615 & 686,346 \\
Maori & 93,939 & 114,117 & 114,429 & 121,185 \\
Pacific Islander & 109,182 & 128,055 & 150,096 & 170,529 \\
Asian & 49,773 & 98,175 & 144,621 & 218,796 \\
MELAA & 2,682 & 7,119 & 12,720 & 17,274 \\
Other & 102 & 153 & 237 & 85,014 \\
TOTAL & 891678 & $1,014,444$ & $1,085,718$ & $1,299,144$ \\
\hline
\end{tabular}


Table 2. Indices of Segregation and Isolation for Auckland's Ethnic Groups: 19912006

\begin{tabular}{lcccc}
\hline & 1991 & 1996 & 2001 & 2006 \\
\hline Indices of segregation & & & & \\
NZ European & .48 & .41 & .42 & .45 \\
Maori & .44 & .38 & .39 & .39 \\
Pacific Islander & .59 & .57 & .58 & .58 \\
Asian & .43 & .38 & .39 & .41 \\
Indices of isolation & & & & \\
NZ European & .83 & .80 & .76 & .74 \\
Maori & .23 & .23 & .22 & .21 \\
Pacific Islander & .38 & .41 & .43 & .44 \\
Asian & .13 & .20 & .26 & .34 \\
Modified Indices of isolation & & & \\
NZ European & .41 & .42 & .38 & .36 \\
Maori & .14 & .13 & .13 & .13 \\
Pacific Islander & .29 & .32 & .34 & .36 \\
Asian & .08 & .11 & .15 & .21 \\
\hline
\end{tabular}


Table 3. Moran's I for the Distributions of Auckland's Four Ethnic Groups, 1991-2006

\begin{tabular}{lrrrr}
\hline & 1991 & 1996 & 2001 & 2006 \\
\hline NZ European & 0.047 & 0.046 & 0.049 & 0.051 \\
Maori & $(172.1)$ & $(166.0)$ & $(179.3)$ & $(184.9)$ \\
& 0.092 & 0.097 & 0.113 & 0.121 \\
Pacific Islanders & $(332.3)$ & $(350.0)$ & $(407.4)$ & $(436.8)$ \\
& 0.108 & 0.119 & 0.138 & 0.151 \\
Asians & $(391.2)$ & $(428.6)$ & $(498.4)$ & $(543.6)$ \\
& 0.054 & 0.055 & 0.057 & 0.058 \\
& $(195.4)$ & $(199.10$ & $(208.1)$ & $(210.1)$ \\
\hline
\end{tabular}

Note: Z-scores are in parentheses 
Table 4. Distribution of Auckland's Meshblocks According to the Statistical Significance of their $G^{*}$ Values for each Ethnic Group: 1991-2006

\begin{tabular}{|c|c|c|c|c|}
\hline & 1991 & 1996 & 2001 & 2006 \\
\hline \multicolumn{5}{|l|}{ NZ European } \\
\hline-0.01 & 1514 & 1588 & 1910 & 2312 \\
\hline-0.05 & 269 & 273 & 334 & 307 \\
\hline Insignificant & 2726 & 2808 & 2723 & 2764 \\
\hline+0.05 & 513 & 599 & 634 & 493 \\
\hline+0.01 & 2928 & 2805 & 2639 & 2540 \\
\hline \multicolumn{5}{|l|}{ Maori } \\
\hline-0.01 & 2281 & 2379 & 2792 & 2985 \\
\hline-0.05 & 593 & 579 & 562 & 634 \\
\hline Insignificant & 2898 & 2889 & 2580 & 2560 \\
\hline+0.05 & 203 & 199 & 177 & 165 \\
\hline+0.01 & 1981 & 2036 & 2132 & 2075 \\
\hline \multicolumn{5}{|c|}{ Pacific Islanders } \\
\hline-0.01 & 2653 & 2750 & 3064 & 3223 \\
\hline-0.05 & 598 & 534 & 566 & 618 \\
\hline Insignificant & 2608 & 2753 & 2497 & 2475 \\
\hline+0.05 & 214 & 205 & 250 & 209 \\
\hline+0.01 & 1883 & 1838 & 1863 & 1889 \\
\hline \multicolumn{5}{|l|}{ Asian } \\
\hline-0.01 & 1041 & 1540 & 1984 & 2507 \\
\hline-0.05 & 749 & 635 & 688 & 599 \\
\hline Insignificant & 3776 & 3319 & 2830 & 2436 \\
\hline+0.05 & 317 & 297 & 263 & 264 \\
\hline+0.01 & 2069 & 2291 & 2474 & 2611 \\
\hline
\end{tabular}

Note: the rows headed $-0.01,-0.05,+0.05$ and +0.01 show meshblocks with $\mathrm{G}^{*}$ values significant at those probability levels of better; the rows headed insignificant shows meshblocks with $\mathrm{G}^{*}$ values statistically insignificant at the 0.05 level. 
Table 5. Distributions of each Auckland Ethnic Group (Percentages of the Group Totals) According to the Classification of Meshblock Clusters, 1991-2006

\begin{tabular}{lrrrr}
\hline & 1991 & 1996 & 2001 & 2006 \\
\hline NZ European & & & & \\
-0.01 & 9.9 & 10.9 & 13.1 & 15.7 \\
-0.05 & 2.7 & 2.7 & 3.8 & 3.3 \\
Insignificant & 34.1 & 35.2 & 34.4 & 35.0 \\
+0.05 & 7.6 & 8.9 & 9.3 & 7.5 \\
+0.01 & 45.7 & 42.3 & 39.4 & 38.5 \\
Maori & & & & \\
-0.01 & 8.7 & 11.0 & 12.5 & 13.8 \\
-0.05 & 3.3 & 3.7 & 3.6 & 4.3 \\
Insignificant & 27.2 & 29.1 & 26.2 & 26.0 \\
+0.05 & 3.7 & 3.1 & 2.8 & 2.8 \\
+0.01 & 57.1 & 53.1 & 55.0 & 53.0 \\
Pacific Islanders & & & & \\
-0.01 & 4.4 & 5.4 & 5.9 & 6.2 \\
-0.05 & 2.2 & 1.9 & 2.0 & 2.6 \\
Insignificant & 23.4 & 25.1 & 21.9 & 22.0 \\
+0.05 & 3.6 & 3.4 & 4.4 & 3.6 \\
+0.01 & 66.3 & 64.2 & 65.9 & 65.7 \\
Asian & & & & \\
-0.01 & 3.7 & 6.4 & 8.2 & 10.2 \\
-0.05 & 4.1 & 3.8 & 4.5 & 3.9 \\
Insignificant & 38.7 & 32.6 & 27.5 & 24.1 \\
+0.05 & 4.8 & 4.7 & 4.1 & 4.0 \\
+0.01 & 48.7 & 52.5 & 55.7 & 57.7 \\
\hline
\end{tabular}

Note: the rows headed $-0.01,-0.05,+0.05$ and +0.01 show meshblocks with $\mathrm{G}^{*}$ values significant at those probability levels of better; the rows headed insignificant shows meshblocks with $\mathrm{G}^{*}$ values statistically insignificant at the 0.05 level. 
Table 6. The Changing Pattern of Residential Clustering for Auckland's Four Ethnic Groups, 1991-2006 (Percentages of Meshblocks According to their 1991 Classification)

\begin{tabular}{lrrrrrrrrrrrrr}
\hline 2006 & - & $\mathrm{I}$ & + & - & $\mathrm{I}$ & + & - & $\mathrm{I}$ & + & - & $\mathrm{I}$ & + \\
\hline 1991 & \multicolumn{1}{c}{ NZ European } & \multicolumn{1}{c}{ Maori } & \multicolumn{1}{c}{ Pacific Islander } & Asian \\
& 73 & 24 & 3 & 90 & 10 & 0 & 94 & 6 & 0 & 62 & 23 & 15 \\
- & 25 & 60 & 15 & 18 & 75 & 7 & 13 & 76 & 11 & 33 & 49 & 18 \\
$\mathrm{I}$ & 2 & 35 & 63 & 0 & 12 & 88 & 2 & 21 & 77 & 2 & 29 & 69 \\
+ & & & 64 & & & 83 & & & 83 & & & 56 \\
\hline
\end{tabular}

Note: - clusters with $\mathrm{G}^{*}$ values of $-2.58<; \mathrm{I}$ - clusters where $\mathrm{G}^{*}$ lies in the range 2.58: $+2.58 ;+$ clusters with $G^{*}$ values of $+2.58<$. 
Table 7. Overlaps in the Classifications of Meshblocks for Auckland's Four Ethnic Groups in 2006

\begin{tabular}{|c|c|c|c|c|c|c|c|c|c|c|}
\hline \multirow[b]{2}{*}{ Pacific Is } & \multicolumn{3}{|c|}{ NZ European } & \multicolumn{3}{|c|}{ Maori } & \multicolumn{4}{|c|}{ Asian } \\
\hline & - & I & + & - & I & + & - & I & + & \\
\hline- & 13 & 42 & 45 & 80 & 19 & 1 & 34 & 33 & 33 & \\
\hline I & 18 & 57 & 25 & 13 & 68 & 19 & 27 & 46 & 27 & \\
\hline+ & 83 & 16 & 1 & 1 & 25 & 74 & 33 & 39 & 28 & \\
\hline & $N Z$ & urol & & & sia & & & & Asia & \\
\hline Maori & - & I & + & - & I & + & $N Z E$ & - & I & + \\
\hline- & 20 & 39 & 41 & 28 & 34 & 38 & & 30 & 32 & 38 \\
\hline I & 20 & 53 & 27 & 28 & 42 & 30 & & 18 & 46 & 36 \\
\hline+ & 63 & 29 & 8 & 42 & 43 & 15 & & 53 & 35 & 12 \\
\hline
\end{tabular}

Note: - clusters with $\mathrm{G}^{*}$ values of $-2.58<; \mathrm{I}$ - clusters where $\mathrm{G}^{*}$ lies in the range 2.58: $+2.58 ;+$ clusters with $G^{*}$ values of $+2.58<$. 
Table 8. The Distribution of Auckland's Meshblocks (Percentage of Total) according to the Combination of Ethnic Groups which are Significantly Over-Represented there

\begin{tabular}{lrrrr}
\hline & 1991 & 1996 & 2001 & 2006 \\
\hline None & 69.8 & 69.0 & 71.3 & 73.1 \\
& & & & \\
All Four & 0 & 0 & 0 & 0 \\
& & & & \\
Pacific Islander, Maori, Asian & 4.8 & 3.7 & 4.1 & 3.5 \\
Pacific Islander, Maori, New Zealand European & 0 & 0 & 0 & 0.2 \\
Pacific Islander, Asian, New Zealand European & 0.1 & 0 & 0 & 0 \\
Pacific Islander, Maori & 9.7 & 11.0 & 12.4 & 13.3 \\
Pacific Islander, Asian & 5.0 & 3.4 & 2.8 & 3.1 \\
Pacific Islander, New Zealand European & 0.2 & 0.6 & 0.7 & 1.2 \\
& & & & \\
Maori, Asian, New Zealand European & 0.1 & 0.1 & 0 & 0 \\
Maori, Asian & 0.7 & 0.7 & 0.7 & 0.4 \\
Maori, New Zealand European & 1.4 & 2.1 & 1.7 & 1.9 \\
& & & & \\
Asian, New Zealand European & 8.3 & 9.3 & 6.3 & 3.6 \\
\hline
\end{tabular}


Table 9. The Sharing of Residential Space in Auckland in 2006: the Percentage Distribution of Each Ethnic Group According to the Combination of Ethnic Groups Significantly Over-Concentrated in each Meshblock

\begin{tabular}{lrrrr}
\hline & NZE & Maori & PI & Asian \\
\hline None & 81.9 & 55.4 & 35.7 & 73.4 \\
& & & & \\
All Four & 0 & 0 & 0 & 0 \\
& & & & \\
Pacific Islander, Maori, Asian & 1.9 & 5.4 & 7.4 & 5.7 \\
Pacific Islander, Maori, New Zealand European & 0 & 0 & 0.1 & 0 \\
Pacific Islander, Asian, New Zealand European & 0 & 0 & 0 & 0 \\
Pacific Islander, Maori & 6.4 & 30.2 & 46.8 & 7.8 \\
Pacific Islander, Asian & 1.8 & 2.9 & 5.9 & 5.7 \\
Pacific Islander, New Zealand European & 1.1 & 1.2 & 1.7 & 0.8 \\
& & & & \\
Maori, Asian, New Zealand European & 0 & 0 & 0 & 0 \\
Maori, Asian & 0.4 & 0.5 & 0.4 & 0.8 \\
Maori, New Zealand European & 2.2 & 2.8 & 1.3 & 0.9 \\
& & & & \\
Asian, New Zealand European & 4.3 & 1.4 & 0.6 & 4.9 \\
\hline
\end{tabular}


Table 10. Percentage Distribution of Meshblocks by Percentage of each Ethnic Group Living there according to the Classification of Meshblocks: Auckland 2001-2006

\begin{tabular}{lrrrrrrrrrrrr}
\hline NZ European & \multicolumn{3}{c}{1991} & \multicolumn{1}{c}{1996} & \multicolumn{3}{c}{2001} & \multicolumn{3}{c}{2006} \\
\hline & - & I & + & - & I & + & - & I & + & - & I & + \\
$0-19$ & 33 & 5 & 2 & 29 & 5 & 1 & 30 & 3 & 1 & 32 & 5 & 2 \\
$20-39$ & 19 & 4 & 0 & 24 & 4 & 0 & 29 & 4 & 0 & 32 & 7 & 1 \\
$40-59$ & 20 & 14 & 1 & 20 & 15 & 2 & 22 & 15 & 4 & 25 & 25 & 3 \\
$60-79$ & 14 & 30 & 11 & 14 & 34 & 19 & 13 & 29 & 25 & 8 & 35 & 25 \\
$80+$ & 14 & 47 & 86 & 13 & 43 & 78 & 6 & 26 & 70 & 3 & 28 & 69 \\
& & & & & & & & & & & & \\
Maori & & 1991 & & & 1996 & & 2001 & & & 2006 \\
& - & I & + & - & I & + & - & I & + & - & I & + \\
$0-19$ & 99 & 93 & 51 & 99 & 91 & 46 & 99 & 92 & 50 & 99 & 93 & 51 \\
$20-39$ & 1 & 6 & 39 & 1 & 8 & 43 & 1 & 7 & 40 & 1 & 7 & 40 \\
$40-59$ & 0 & 1 & 8 & 0 & 0 & 10 & 0 & 1 & 9 & 0 & 0 & 8 \\
$60-79$ & 0 & 0 & 1 & 0 & 0 & 1 & 0 & 0 & 1 & 0 & 0 & 1 \\
$80+$ & 0 & 0 & 0 & 0 & 0 & 0 & 0 & 0 & 0 & 0 & 0 & 0
\end{tabular}

\begin{tabular}{lrrrrrrrrrrrr} 
Pacific Islander & 1991 & \multicolumn{3}{c}{1996} & \multicolumn{3}{c}{2001} & \multicolumn{3}{c}{2006} \\
& - & I & + & - & I & + & - & I & + & - & I & + \\
$0-19$ & 100 & 90 & 39 & 99 & 88 & 35 & 99 & 86 & 28 & 99 & 85 & 26 \\
$20-39$ & 0 & 8 & 29 & 1 & 9 & 28 & 1 & 12 & 27 & 1 & 13 & 27 \\
$40-59$ & 0 & 1 & 21 & 0 & 2 & 19 & 0 & 2 & 21 & 0 & 2 & 22 \\
$60-79$ & 0 & 1 & 9 & 0 & 1 & 15 & 0 & 0 & 17 & 0 & 0 & 17 \\
$0+$ & 0 & 0 & 1 & 0 & 0 & 3 & 0 & 0 & 7 & 0 & 0 & 8
\end{tabular}

\begin{tabular}{lrrrrrrrrrrrrr} 
Asian & \multicolumn{3}{c}{1991} & \multicolumn{3}{c}{1996} & \multicolumn{3}{c}{2001} & \multicolumn{3}{c}{2006} \\
& - & I & + & - & I & + & - & I & + & - & I & + \\
$0-19$ & 99 & 98 & 89 & 99 & 94 & 64 & 98 & 86 & 45 & 96 & 73 & 25 \\
$20-39$ & 1 & 2 & 10 & 1 & 6 & 30 & 2 & 12 & 43 & 4 & 22 & 44 \\
$40-59$ & 0 & 0 & 1 & 0 & 0 & 4 & 0 & 1 & 11 & 0 & 3 & 24 \\
$60-79$ & 0 & 0 & 0 & 0 & 0 & 1 & 0 & 1 & 1 & 0 & 1 & 6 \\
$80+$ & 0 & 0 & 0 & 0 & 0 & 1 & 0 & 0 & 0 & 0 & 0 & 1 \\
\hline
\end{tabular}

Note: - clusters with $\mathrm{G}^{*}$ values of $-2.58<$; I - clusters where $\mathrm{G}^{*}$ lies in the range 2.58: +2.58 ; + clusters with $\mathrm{G}^{*}$ values of $+2.58<$. 


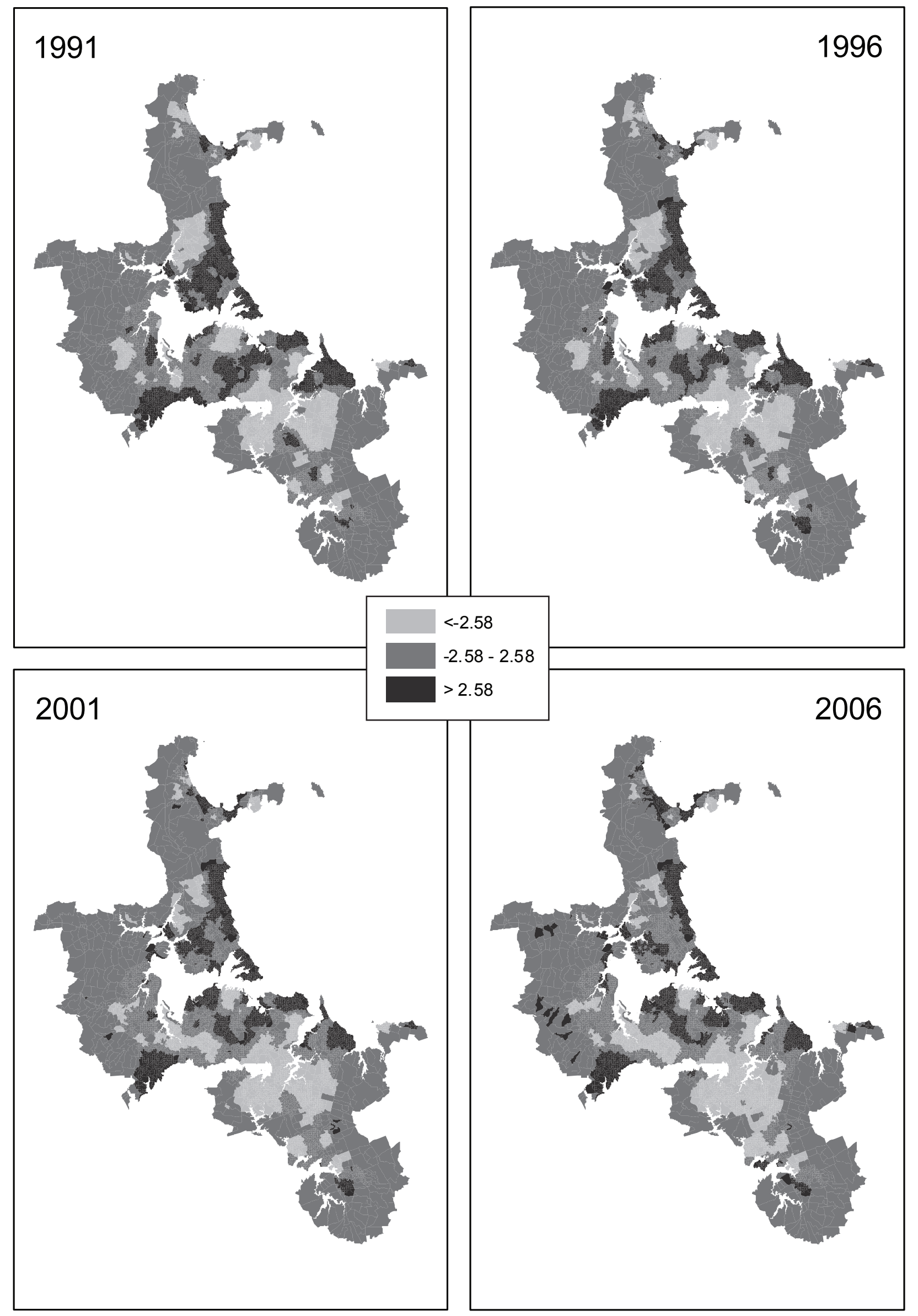

Figure 1.The clusters within Auckland where New Zealand Europeans were significantly over- $\left(G^{*}=+2.58<\right)$ and under- $\left(G^{*}=-2.58<\right)$ at the four census dates. 


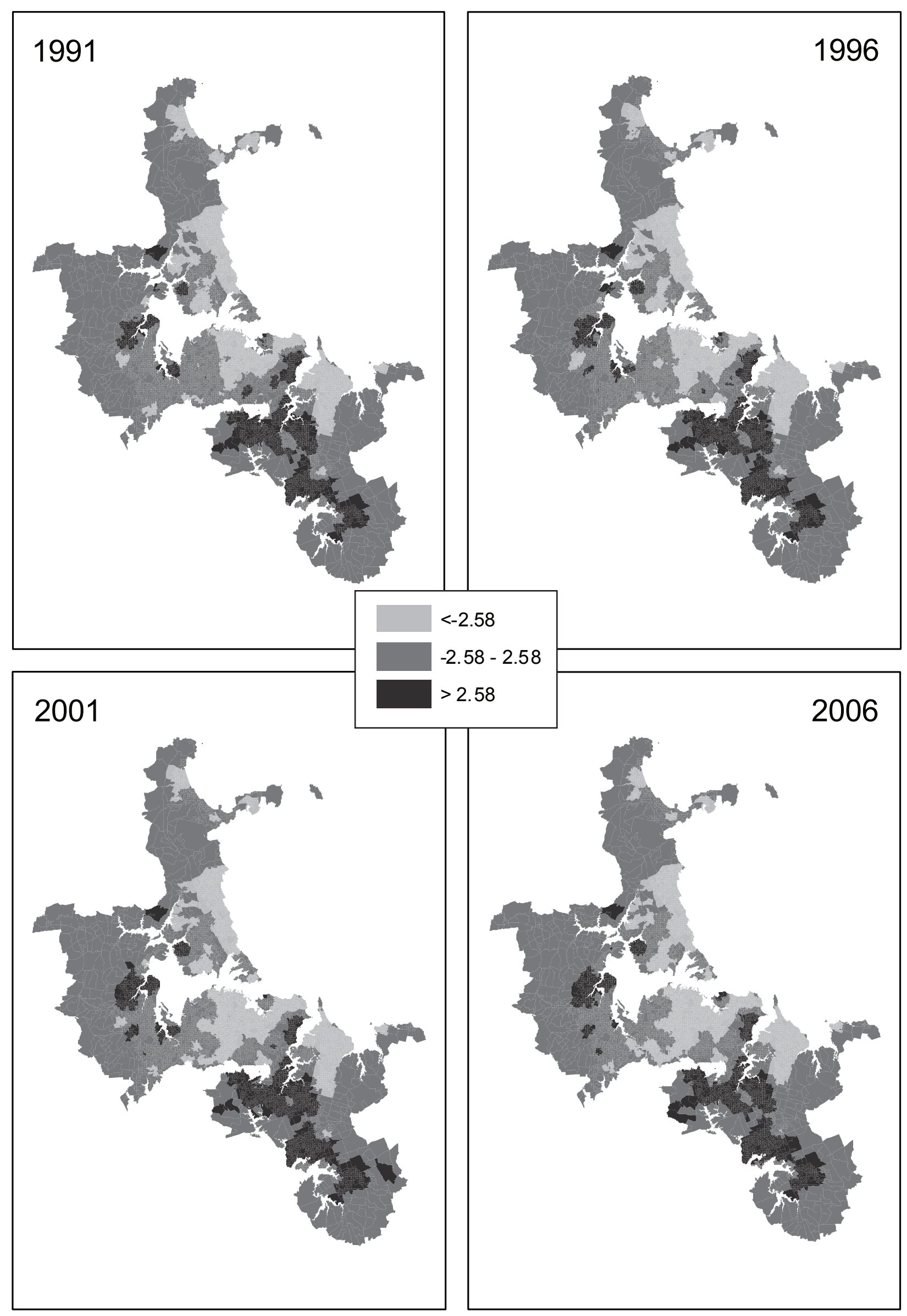

Figure 2. The clusters within Auckland where Maori were significantly over- $\left(G^{*}=+2.58<\right)$ and under- $\left(G^{*}=-2.58<\right)$ at the four census dates. 


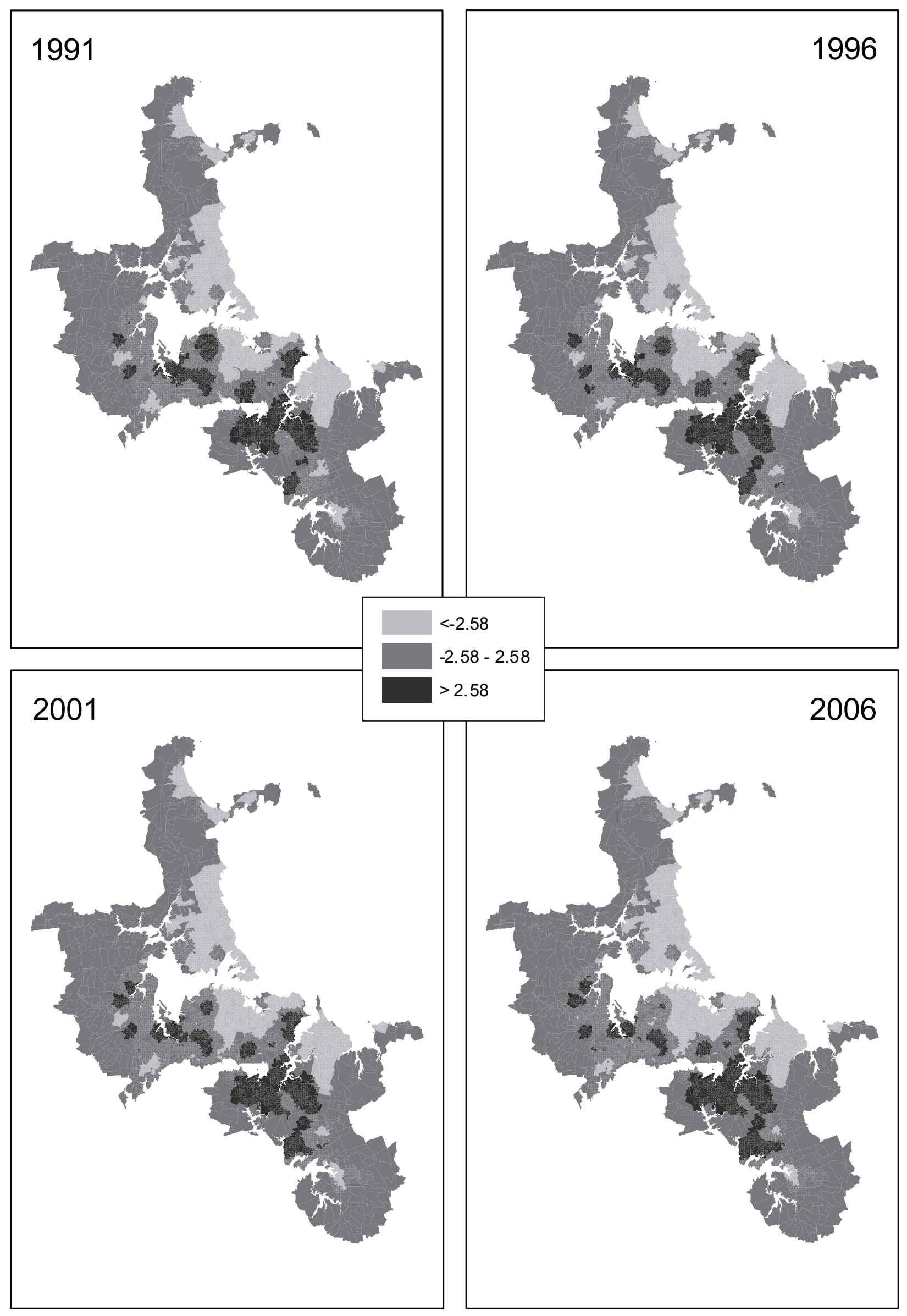

Figure 3. The clusters within Auckland where Pacific Islanders were significantly over$\left(G^{*}=+2.58<\right)$ and under- $\left(G^{*}=-2.58<\right)$ at the four census dates. 


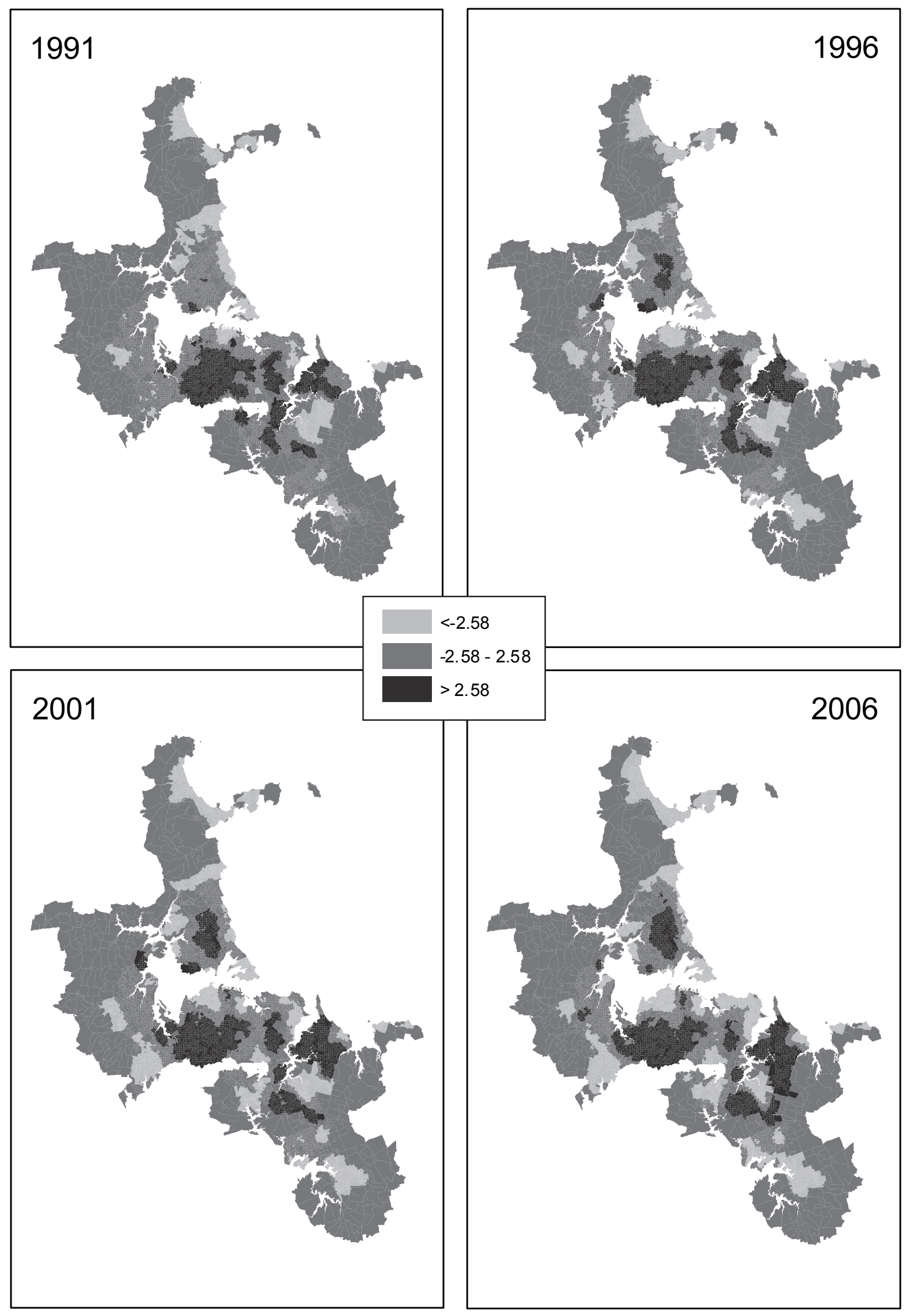

Figure 4. The clusters within Auckland where Asians were significantly over$\left(G^{*}=+2.58<\right)$ and under- $\left(G^{*}=-2.58<\right)$ at the four census dates. 


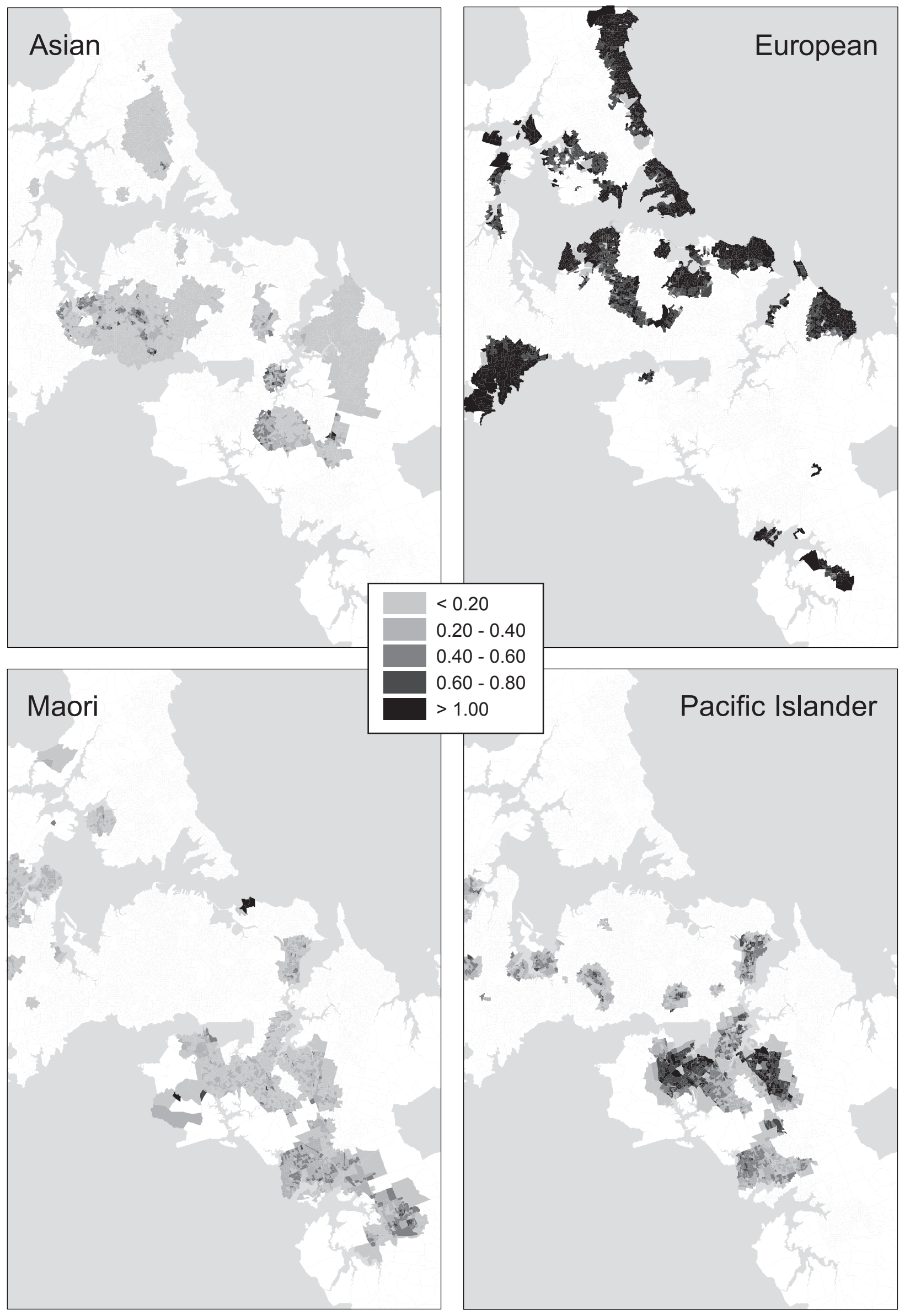

Figure 5. The proportion of the meshblock population for each group within the clusters where it was significantly over-represented in 2006 